\title{
Lactose in dairy ingredients: Effect on processing and storage stability ${ }^{1}$
}

\author{
Thom Huppertz ${ }^{2}$ and Inge Gazi \\ NIZO Food Research, PO Box 20, 6710BA, Ede, the Netherlands
}

controlled, and optimized. Routes to achieve this are outlined in this review paper.

Key words: amorphous lactose, lactose crystallization, stickiness, caking, glass transition

\section{INTRODUCTION}

In the milk of most common dairying species, lactose [ $\beta$-D-galactopyranosyl- $(1 \rightarrow 4)$-D-glucose] is the most abundant constituent after water. In addition to being unique to milk, lactose is also the main carbohydrate in the milk of virtually all mammalian species. Smaller amounts of mono- and oligosaccharides may also be present in the milk of most species, with particularly the latter having a crucial nutritional role. From a technological perspective, lactose is the most important carbohydrate in milk and its behavior can have a strong effect on a variety of dairy products. For instance, it is crucial in the fermentation by lactic acid bacteria in the preparation of yogurt and many other acid-coagulated dairy products, as well as in many cheese varieties (Walstra et al., 2005). Furthermore, lactose can be isolated and subsequently applied in a wide range of dairy and nondairy food products, as well as in nonfood products (Holsinger, 1997). Lactose is used as the source material for several lactose derivatives, including galacto-oligosacchrides, lactulose, lactitol, and lactobionic acid (Gänzle et al., 2008). Furthermore, because lactose is a reducing carbohydrate, it can participate in the Maillard reaction, which can occur in heated dairy products, particularly when heated at sterilization conditions (Walstra et al., 2005).

A further category of dairy products in which lactose plays a key role is in dairy ingredients. In virtually all dairy ingredients, lactose is present, ranging from either large concentrations (e.g., lactose, permeate, and whey powders) to low concentrations or even trace levels (e.g., caseinate, whey protein isolate, milk protein isolate). Particularly in ingredients where lactose constitutes more than $50 \%$ of DM (e.g., skim milk powder, whey powder, permeate powder), lactose has a strong effect on the behavior and properties of the ingredients during processing and storage. Particularly notable effects are on the powder handling properties such as stickiness and caking behavior of powder particles during drying 
and during storage, particularly at elevated temperature and water activity $\left(\mathbf{A}_{\mathrm{w}}\right.$; Kelly, 2009). Because caking and stickiness of ingredients can present big issues for the dairy industry, considerable effort has been dedicated to understanding these phenomena (O'Callaghan and Hogan, 2013). With increased understanding of the underlying mechanisms of stickiness and caking of powder particles, the realization has grown that control of the behavior of lactose in dairy ingredient powders containing high levels of lactose, as well as in products containing high levels of lactose (e.g., infant formula) is required to ensure desired powder handling properties and powder stability.

In this review, we will focus on the behavior of lactose in dry dairy ingredients and the effect thereof on powder handling properties and powder stability. Particular emphasis will be paid to the aforementioned lactoserich dairy products (e.g., milk powder, whey powder, and permeate powder). Pure lactose powder is largely outside the scope of this review but is dealt with extensively by Paterson (2009) and Wong and Hartel (2014). To place the behavior of lactose in relation to the properties of these industrially relevant powders, the effect of concentration and drying will be considered. Particular focus will be paid to the state of lactose (i.e., amorphous, crystalline, or both) in dairy ingredients and factors determining it, the distribution of lactose between the surface and the bulk of the powder, and how these factors affect powder handling properties and browning in powders.

\section{PHYSICAL AND CHEMICAL PROPERTIES OF LACTOSE IN SOLUTION}

All dried dairy ingredients are produced from liquid dairy streams. This may be (standardized) milk or whey from the manufacture of cheese, Greek-style yogurt, or acid casein. In addition, lactose-rich dairy ingredients can be prepared from ultrafiltration permeates of milk or whey. Hence, before considering the influence of lactose on handling and storage properties of dried dairy ingredients, it is important to first consider the properties of lactose in solution, and how these are affected by the presence of proteins and salts.

\section{Mutarotation}

One important property of lactose to consider is that 2 anomers of lactose are observed (i.e., $\alpha$-lactose and $\beta$-lactose), which have specific optical rotations $[\alpha]_{D}^{20}$ of +89.4 and $+35^{\circ}$, respectively (Walstra and Jenness, 1984; Holsinger, 1997). The conversion between these forms of lactose occurs via the open chain form of the glucose moiety of lactose. An equilibrium will establish at $[\alpha]^{20}{ }_{\mathrm{D}}=+55.3^{\circ}$, representing $\sim 37 \% \quad \alpha$-lactose and $63 \%$-lactose (Walstra and Jenness, 1984; Holsinger, 1997). This equilibrium is dependent on both lactose concentration and temperature, with increases in both these parameters shifting the equilibrium optical rotation to lower values (i.e., to somewhat a higher percentage of $\beta$-lactose). The $\mathrm{pH}$ does not affect the equilibrium value. Hence, at typical conditions encountered in the dairy industry, lactose in solution should be considered a mixture of $\alpha$ - and $\beta$-lactose.

Although it does not affect the mutarotation equilibrium, $\mathrm{pH}$ does strongly affect the rate at which the equilibrium establishes; the minimum in mutarotation rate is found at $\mathrm{pH} 5$, and particularly $\mathrm{pH}<2$ and $\mathrm{pH}$ $>7$ result in very rapid mutarotation (Walstra and Jenness, 1984; Holsinger, 1997). The rate of mutarotation also increases rapidly with increasing temperature [i.e., $\sim 2.8$-fold for every $10^{\circ} \mathrm{C}$ temperature increase (Walstra and Jenness, 1984)]. Hence, whereas it may take hours for equilibrium to establish at room temperature, this only takes minutes or less at temperatures $>70^{\circ} \mathrm{C}$. In addition, mutarotation rate of lactose is strongly enhanced by the presence of milk salts. Mutarotation rate was found to be 1.8- and 2.2-fold higher in a simulated milk ultrafiltrate compared with water for $\alpha$-lactose and $\beta$-lactose, respectively (Haase and Nickerson, 1966).

\section{Solubility}

One aspect that is strongly affected by the different anomers of lactose is solubility, which is rather low compared with many other mono- and disaccharides. Lactose solubility can be described by the function $\mathrm{C}_{\mathrm{LAC}}=10.9109 \times \mathrm{e}^{0.02804 \mathrm{~T}}$, where $\mathrm{C}_{\mathrm{LAC}}$ is the concentration of lactose in grams per $100 \mathrm{~g}$ of water and $\mathrm{T}$ is the temperature in degrees Celsius (Butler, 1998; Paterson, 2009). From this equation, it follows that at $20^{\circ} \mathrm{C}$, solubility of lactose is $\sim 20 \mathrm{~g}$ of anhydrous lactose per $100 \mathrm{~g}$ of water, which increases to $\sim 30,60$, or $100 \mathrm{~g}$ of lactose per $100 \mathrm{~g}$ of water at 40,60 , or $80^{\circ} \mathrm{C}$, respectively.

When dissolving lactose, the rate of dissolution depends strongly on the type used. $\alpha$-Lactose has a lower solubility in water, so when an overdose of $\alpha$-lactose is added to water, the initial solubility will be at the solubility limit of $\alpha$-lactose in water; subsequently, however, some $\alpha$-lactose will be converted to $\beta$-lactose, and as a result the solution becomes unsaturated again and more $\alpha$-lactose can dissolve. This process will continue until the final equilibrium between $\alpha$-lactose and $\beta$-lactose is achieved. The solubility of $\alpha$-lactose increases strongly with temperature, whereas that of $\beta$-lactose shows considerably less temperature dependence (Hodges et al., 1993; Lowe and Paterson, 1998; Walstra et al., 2005; Paterson, 2009). When lactose solutions are con- 
centrated, the aforementioned solubility of lactose can be exceeded considerably before crystallization occurs. This supersolubility of lactose is typically equal to the solubility at a temperature $30^{\circ} \mathrm{C}$ higher. In addition, experimental conditions, particularly agitation, strongly affect supersolubility (Paterson, 2009).

For understanding lactose solubility in dairy liquids (e.g., milk, whey, or permeate), rather than in pure aqueous solution, the influence of other constituents on lactose solubility should be considered. In many cases, it is observed that lactose solubility, expressed as grams of lactose per gram of water, is lower in dairy liquids than in pure lactose solutions. This can first of all be related to the water-binding properties of the other constituents, necessitating the expression of lactose solubility per gram of available water rather than per gram of water. Particularly proteins and polysaccharides can have high water-binding capacity (Walstra et al., 2005) and can hence reduce solubility. The reduced solubility of lactose on addition of lactic acid or lactate (Smart, 1988; Smart and Smith, 1992) may also be attributable to the unavailability of a fraction of the water as a solvent for lactose.

The addition of sodium phosphate was also found to reduce lactose solubility (Smart, 1988; Smart and Smith, 1992), whereas addition of potassium phosphate increased it (Bhargava and Jelen, 1996). Phosphate is classified as a water-structure-making ion (Marcus, 2010); due to the high charge density of water-structure-making ions, water molecules become oriented, thereby reducing the solubility of, for example, lactose. In the case of potassium phosphate, the water-structure-breaking capability of potassium can actually overpower the water-structure-making capacity of phosphate, thereby increasing solubility. On the other hand, sodium is not a water-structurebreaking ion (Marcus, 2010) as a result of which the water-structure-making effect of phosphate causes the decreased solubility of lactose on sodium phosphate addition. Calcium chloride addition had little effect on lactose solubility (Smart, 1988; Smart and Smith, 1992; Bhargava and Jelen, 1996), which can be understood when considering that calcium chloride addition combines the effects of a water-structure-making ion $\left(\mathrm{Ca}^{2+}\right)$ with a water-structure-breaking ion $\left(\mathrm{Cl}^{-}\right)$, yielding an overall limited net effect. In addition to a potential net water-structure-making or -breaking effect, solubility of the salts should also be considered. Although both $\mathrm{Ca}^{2+}$ and $\mathrm{PO}_{4}{ }^{3-}$ could be expected to reduce lactose solubility through their water-structure-making effects (Marcus, 2010), the limited solubility of calcium phosphate prevents such effects to be observed (Smart, 1988; Smart and Smith, 1992). Hence, to understand lactose solubility in dairy systems, lactose solubility in pure water should be corrected for water unavailable due to binding to other constituents, and for the effect of particularly salts on water structure. Based hereon, increased lactose yield and reduced solubility after nanofiltration of whey permeate or milk permeate (Guu and Zall, 1992; Mikkonen et al., 2001) is to be expected. Particularly the removal of potassium during nanofiltration could be important in this respect.

\section{Lactose Crystallization from Solutions}

When solubility of lactose is exceeded (e.g., through removal of water or a reduction in temperature), crystallization can occur. Various lactose crystal forms can theoretically be formed, but for crystallization from liquid in dairy products under normal industrial conditions, the main crystalline form in which lactose is found is the $\alpha$-lactose monohydrate form. This is also the most stable crystalline form. These $\alpha$-lactose monohydrate crystals are very hard, slightly hygroscopic, and dissolve slowly. If crystallization occurs at temperatures above $93.5^{\circ} \mathrm{C}$, anhydrous $\beta$-lactose crystals form. Crystalline $\beta$-lactose shows little hygroscopicity and good solubility. Crystalline $\beta$-lactose is unstable and over time, pending the availability of sufficient moisture for hydration, will transform into the stable $\alpha$-lactose monohydrate from.

During spray drying in the preparation of, for example, milk powder, water removal is too rapid for crystallization to occur. Instead, amorphous lactose present in a glassy state is formed, which also contains some water. Amorphous lactose is hygroscopic and when sufficient water is adsorbed, molecular mobility is enhanced to such an extent that crystallization to $\alpha$-lactose monohydrate can occur. The (in)stability of the amorphous lactose in dairy powders is strongly related to many storage and handling problems of these powders and is dealt with in detail in subsequent sections.

Lactose crystallization can be considered a 2-step process, consisting of (1) nucleation, followed by (2) crystal growth. When the supersolubility is exceeded, spontaneous nucleation can occur, whereas for lower lactose concentrations still above the solubility limit, forced nucleation, either by flash cooling or addition of seeding crystals, is required to initiate crystallization. Further growth of crystals depends on the degree of saturation of the solution as well as temperature. Temperature affects lactose solubility and hence the degree of supersaturation, which at a given concentration would thus increase at lower temperature; however, at a given absolute degree of supersaturation, temperature does not affect nucleation rate (McLeod et al., 2011), whereas crystallization speed increases with absolute degree of supersaturation and temperature (Jelen and 
Coulter, 1973b). Furthermore, temperature also influences crystallization through mutarotation; due to the crystallization of lactose as $\alpha$-lactose monohydrate, the degree of supersaturation of $\alpha$-lactose in solution decreases and the ratio $\alpha$-lactose $/ \beta$-lactose decreases. Conversion of $\beta$-lactose to $\alpha$-lactose will occur until equilibrium is reached, increasing supersaturation of $\alpha$-lactose again. The increased rate of mutarotation at higher temperature thus facilitates the crystallization process. Likewise, $\mathrm{pH}$ can also affect mutarotation rate, as can the presence of milk salts. The importance of the mutarotation step was also highlighted in the kinetic model for lactose crystallization proposed by Mimouni et al. (2009).

The presence of whey proteins promotes nucleation but slows down the growth of lactose crystals (Mimouni et al., 2005; Gernigon et al., 2013). Mimouni et al. (2005) explained this by considering that water binding by the proteins creates areas of supersaturation of lactose, which are favorable for nucleation. In spite of the rapid nucleation that led to the formation of many small crystals, the growth of the crystals was found to occur at a relatively slow rate.

The effect of various salts on lactose crystallization speed or lactose crystal growth rate has been studied. Sodium phosphate promotes crystallization (Jelen and Coulter, 1973a; Smart, 1988; Smart and Smith, 1992), whereas potassium phosphate retards crystallization (Bhargava and Jelen, 1996). This is in line with observed effects on lactose solubility. Jelen and Coulter (1973a) reported that lactic acid reduced the growth of lactose crystals added to supersaturated lactose solutions, but crystallization experiments by Smart (1988), Smart and Smith (1992), and Gernigon et al. (2013) did not confirm these findings. Lactate salts [i.e., calcium lactate (Bhargava and Jelen, 1996), sodium lactate and lithium lactate (Smart, 1988; Smart and Smith, 1992)] were all found to enhance lactose crystallization. Furthermore, galacto-oligosacchrides were found to reduce lactose crystallization (Smart and Smith, 1992; Ihli and Paterson, 2015). Lactose-phosphate, which can be formed through fermentation by lactic acid bacteria and can be found in whey and whey permeates, inhibits the growth of lactose crystals, probably by incorporation as an impurity in the crystal lattice (Visser 1984, 1988; Lifran et al., 2007).

\section{PROPERTIES OF LACTOSE IN DAIRY POWDERS}

\section{Water Sorption}

Powder handling issues attributed to lactose are often the result of moisture sorption by lactose. Mois- ture sorption isotherms are the most convenient and applied technique to study moisture sorption phenomena. When interpreting the outcomes hereof in relation to powder handling issues, it is important to realize that in most cases moisture adsorption isotherms are determined, which is representative for issues encountered when powders are exposed to a humid environment. However, when relating moisture relationships to problems occurring during drying, moisture desorption isotherms are actually more appropriate. For typical dairy powders such as skim milk powder and whey powder, moisture sorption and desorption isotherms do not overlap; typically, the desorption isotherm shows higher values for moisture content than the adsorption isotherm (Kinsella et al., 1986). Hence, during drying, powders may have higher water moisture content than would be expected from sorption isotherms. These effects, however, are primarily related to water binding by macromolecules (e.g., proteins or polysaccharides) and not to small carbohydrates such as lactose.

When considering moisture sorption by lactose, it is important to distinguish between amorphous and crystalline lactose. Crystalline lactose shows little water sorption at $\mathrm{A}_{\mathrm{w}}<0.85$ and considerable water sorption only observed at higher values of $\mathrm{A}_{\mathrm{w}}$ (Bronlund and Paterson, 2004). Water sorption of crystalline lactose shows virtually no temperature dependence in the temperature range 12 to $37^{\circ} \mathrm{C}$ (Bronlund and Paterson, 2004). Water sorption of amorphous lactose also shows little temperature dependence in these temperature regions, but is considerably higher than that of crystalline lactose (Berlin et al., 1968; Jouppila and Roos, 1994b; Bronlund and Paterson, 2004). Moisture sorption of amorphous lactose increases in near-linear fashion with increasing $\mathrm{A}_{\mathrm{w}}$ up to 0.3 , above which a more exponential increase in water sorption was observed with increasing $\mathrm{A}_{\mathrm{w}}$. At water activities $>0.4$, a characteristic desorption break occurs in the sorption isotherm of amorphous lactose (Berlin et al., 1968; Jouppila and Roos, 1994b; Bronlund and Paterson, 2004), as well as in products containing high levels of amorphous lactose [e.g., skim milk powder or noncrystallized whey powder (Berlin et al., 1968; Lai and Schmidt, 1990; Roos and Karel, 1992; Jouppila and Roos, 1994b; Schuck et al., 2005; Ibach and Kind, 2007; Shrestha et al., 2007)].

This desorption break can be attributed to the crystallization of amorphous lactose to $\alpha$-lactose monohydrate, leading to the release of water and weight loss (Berlin et al., 1968; Jouppila and Roos, 1994a,b). However, it is important to keep in mind that this weight loss occurs when a driving force to maintain the relative humidity of the surrounding environment is present (i.e., as in the measurements of sorption isotherm). 
However, when this occurs in a closed environment (e.g., a bag or can of powder), continuous conditioning of the outside air of course does not occur, and as a result relative humidity will increase, further promoting reactions that are enhanced at higher $\mathrm{A}_{\mathrm{w}}$.

Sorption behavior of dairy powders can be largely understood from the sorption behavior of the individual components. Berlin et al. (1968) predicted sorption isotherms of skim milk powder acceptably from the contribution of the casein micelles, whey proteins, lactose, and salts in the milk serum. Foster et al. (2005) extended this approach over a wider temperature range. At $\mathrm{A}_{\mathrm{w}}<0.3$, water sorption by the milk proteins is more extensive than that of lactose, whereas the milk serum salts show virtually no moisture sorption at $\mathrm{A}_{\mathrm{w}}<0.6$ (Berlin et al., 1968). At $\mathrm{A}_{\mathrm{w}}>0.3$, moisture sorption of the amorphous lactose increases strongly up to the point of crystallization of lactose (Berlin et al., 1968). The formed $\alpha$-lactose monohydrate shows little or no moisture sorption up to $\mathrm{A}_{\mathrm{w}}=0.85$ (Berlin et al., 1968; Bronlund and Paterson, 2004). At $\mathrm{A}_{\mathrm{w}}>$ 0.6 , the milk serum salts start showing strong moisture sorption and become strong contributors to water sorption (Berlin et al., 1968), particularly in products where protein content is low (e.g., milk or whey permeate, or whey from Greek-style yogurt or quark manufacture). As outlined above, crystalline $\alpha$-lactose monohydrate strongly contributes to moisture sorption at $A_{w}>0.85$.

\section{Phase Transitions of Lactose in Dairy Powders}

One of the main effects of moisture sorption by dairy powders is that it can cause phase transitions in lactose. As outlined previously, water removal during spraydrying is so rapid that crystallization of lactose cannot occur, or only to a limited extent. As a result, lactose forms a solid-like amorphous glass directly from the liquid state. This glassy state is a nonequilibrium state, so a drive toward thermodynamic equilibrium (i.e., to the crystalline state) will occur. In general, molecular mobility in the glassy state is limited to molecular rotations and vibrations as the molecules are frozen in their position (Roos, 2010). Hence, amorphous glasses can be considered to be rather stable and their material characteristics can be considered as solid-like. When a glass is heated, it undergoes a solid-liquid revisable transition known as the glass transition (Roos, 2010). The temperature at which this transition occurs is referred to as the glass transition temperature. Glass transitions are typically determined by differential scanning calorimetry, where they appear as endothermic changes in heat capacity. The glass transition occurs over a temperature range, often characterized by an onset temperature, a midpoint temperature, and an endpoint temperature (Roos, 2002, 2010).

Water acts as a plasticizer in the amorphous lactose matrix, as a result of which the glass transition temperature is decreased. The extent to which water reduces the glass transition temperature can be predicted using the Gordon and Taylor equation (Gordon and Taylor, 1952), which relates the decrease in glass transition temperature to the weight fractions and the glass transition temperatures of the amorphous solids and amorphous water. The glass transition temperature of anhydrous amorphous lactose was reported as $101^{\circ} \mathrm{C}$ (Jouppila and Roos, 1994a) or $115^{\circ} \mathrm{C}$ (Brooks, 2000), whereas that of skim milk solids was reported as $92^{\circ} \mathrm{C}$ from the data of Jouppila and Roos (1994a), suggesting that the glass transition of skim milk solids is largely determined by lactose. Using this approach, Jouppila and Roos (1994a) observed that when the glass transition temperature of various milk powders was expressed as a function of skim milk solids (i.e., corrected for fat and moisture content), a close similarity was observed to values for amorphous lactose. Lactose hydrolysis led to strong deviations from this curve (Jouppila and Roos, 1994a), further substantiating findings that the glass transition temperature of milk powders is determined primarily by lactose and water. This has subsequently been substantiated in various other systems [e.g., powders containing lactose and intact or hydrolyzed whey protein isolate (Hogan and O'Callaghan, 2013) or sodium caseinate (Mounsey et al., 2012)], as well as in samples with increased or reduced milk protein content (Shrestha et al., 2007; Silalai and Roos, 2010).

One of the changes associated with the glass transition is a reduction in viscosity. Paterson et al. (2015) recently determined the viscosity of amorphous lactose to be $\sim 1.1 \times 10^{14} \mathrm{~Pa} \cdot \mathrm{s}$ at the glass transition point. They also suggested that viscosity for amorphous lactose as a function of temperature can be predicted by the Williams-Landel-Ferry equation (Williams et al., 1955), using the constants as originally suggested by Williams et al. (1955) or those suggested by Peleg (1992). The data from Paterson suggest a decrease in viscosity of one order of magnitude when the temperature is $\sim 6^{\circ} \mathrm{C}$ above the glass transition.

Amorphous glasses are plasticized (softened) by water, as a result of which glass transition temperatures are reduced (Roos, 2010). If sufficient moisture is sorbed and the glass transition temperature is reduced below ambient, the change in state can result in sufficient mobility that crystallization of lactose can occur. For pure amorphous lactose, this is typically observed at a relative humidity of $\sim 0.3$ to 0.4 . In sorption isotherms, this is characterized by a weight loss due to the loss 
of moisture because amorphous lactose contains more water than the crystalline forms of lactose. Jouppila and Roos (1994a,b) determined that skim milk powder and lactose showed crystallization at the same relative humidity, but that lactose crystallization was much slower in skim milk powder than in pure lactose. This was attributed to the presence of milk proteins and salts delaying the crystallization of lactose in skim milk powder, which was subsequently confirmed in model systems containing lactose and whey protein isolate, or hydrolyzed whey protein (Hogan and O'Callaghan, 2013), sodium caseinate (Haque and Roos, 2004a,b, 2006; Mounsey et al., 2012), or hydrolyzed sodium caseinate (Mounsey et al., 2012). A delaying effect of salts on lactose crystallization was confirmed in the studies of Omar and Roos (2007a,b), showing a particularly large effect of calcium chloride.

Similar delaying effects of milk salts and milk proteins were observed by Ibach and Kind (2007), who compared the crystallization kinetics of lactose in amorphous lactose, whey permeate powder, and whey powder. Crystallization of lactose in these powders was found to be quicker at higher temperatures and higher relative humidities (Ibach and Kind, 2007), similar to observations by Jouppila and Roos (1994a) who showed that the instant crystallization temperature of lactose decreased with increasing relative humidity. Milk fat was reported to decrease the rate of crystallization of lactose (Jouppila and Roos, 1994a), which is probably related primarily to the fact that the presence of fat on the surface of the powder particles decreases the rate of moisture sorption (Kelly, 2009).

The conditions at which crystallization of lactose in powders occurs determine the particular crystal forms of lactose observed. $\alpha$-Lactose monohydrate is the most stable crystalline form of lactose. However, it is also the slowest to form and requires the presence of sufficient water for hydration. Hence, $\alpha$-lactose monohydrate is found to form primarily at conditions where crystallization is slow, mutarotation is enhanced, and sufficient moisture is present. In practice, this translates to low temperatures, the presence of, for example, milk salts to enhance mutarotation and comparatively high water activities. In other conditions, e.g., when rapid crystallization occurs due to high temperatures, anhydrous mixtures of $\alpha$-lactose and $\beta$-lactose, or anhydrous $\beta$-lactose forms in milk, whey, or permeate powder (Saito, 1988; Aguilera et al., 1995; Jouppila et al., 1998; Drapier-Beche et al., 1999; Nijdam et al., 2007). The less stable $\beta$-lactose can eventually transform to the more stable $\alpha$-lactose monohydrate over time, given the availability of sufficient water, but this process can be slow.

\section{Location of Lactose in Powder Particles}

Powder particles in spray-dried dairy products should not be considered homogeneous. Initial studies by Fäldt and Sjöholm (1996) and Fäldt and Bergenståhl (1994, 1996) showed that compared with the average composition of the product, fat, and protein are overrepresented at the powder particle surface, whereas lactose concentration is lower on the particle surface than in the core of the powder particle. Later studies by Kim et al. (2002, 2003) and Fyfe et al. (2011) showed similar trends. For instance, for powders containing sodium caseinate and lactose at a 20/80 weight ratio, the powder particle surface protein/lactose ratio was $70 / 30$ (Fäldt and Bergenståhl, 1994). For a powder containing $99 \%$ lactose and 1\% whey protein, Islam et al. (2013) reported protein to represent almost $60 \%$ of the surface composition.

Crystallization of lactose in the powders and concomitant damage of emulsion droplets was found to increase fat content and reduce lactose content on the particle surface of spray-dried emulsions even further (Fäldt and Bergenståhl, 1996). Kim et al. (2003) related the different composition of the powder particle surface compared with the bulk of the powder particle to solid/ solute segregation in the drying droplets. This is based on the fact that during drying, water will diffuse toward the surface of the particles, and solutes toward the center of the particles due to concentration gradients formed as a result of evaporation of water from the particle surface. The extent to which this happens for different compounds is highly dependent on the diffusion coefficient of the solutes. When considering dairy products, diffusion of lactose and salts is of the same order of magnitude, but diffusion of the considerably larger whey proteins, casein micelles, and fat globules is orders of magnitude lower. Hence, although some lactose and salts can diffuse to the center of the particle during drying, diffusion of whey proteins, casein micelles, or fat globules will be far more limited. When peptides rather than intact proteins are used, surface coverage by lactose is higher (Hogan and O'Callaghan, 2013), which can be related to the fact that the smaller peptides diffuse to the particle center more readily than the intact proteins.

\section{INFLUENCE OF LACTOSE ON DAIRY INGREDIENT MANUFACTURE AND POWDER PROPERTIES}

Stickiness and caking are 2 specific handling problems of dairy powders that can strongly be affected by lactose. Stickiness may be observed during drying and manifest itself as powder particles sticking to the dryer 
or fluid bed. In addition to the negative aspects of stickiness, it is also exploited in the agglomeration of powders (Kelly, 2009; O'Callaghan and Hogan, 2013). Caking can occur during storage of powders and manifests itself as the formation of lumps in previously free-flowing powders; caking is typically preceded by stickiness of powder particles after which solid bridges form between particles (Listiohadi et al., 2005; Kelly, 2009). Both stickiness and caking of powders are strongly related to the composition of the powders, with particularly high carbohydrate content and low molecular weight carbohydrates increasing the propensity to stickiness and caking. In addition, environmental conditions (i.e., temperature and humidity) strongly affect stickiness and caking. This can to a considerable extent be related to the glass transition of lactose or other carbohydrates present in the powders (Listiohadi et al., 2005; Kelly, 2009; O'Callaghan and Hogan, 2013).

\section{Lactose-Induced Stickiness}

The formation of liquid bridges as a result of surface energy-driven viscous flow during powder particle contact has been described as the cause of stickiness of powders (Downton et al., 1982). If sufficient liquid flow can occur between the particles to form a bridge and the bridge is strong enough to resist deformation, stickiness occurs. The resistance to flow is determined by the viscosity (Downton et al., 1982). In the glassy state, viscous flow does not occur, but as described previously, the viscosity of amorphous carbohydrates decreases strongly with increasing temperature above the glass transition temperature (Roos, 2010; Paterson et al., 2015). Sticking of powder particles can be relevant over different time scales; during processing, contact times in the order of seconds or less are encountered. For a 7:1 mixture of sucrose and fructose, Downton et al. (1982) determined the critical viscosity during a 1 to $10 \mathrm{~s}$ time period to be in the range $10^{6}$ to $10^{8} \mathrm{~Pa} \cdot \mathrm{s}$. However, during storage, contact times are considerably longer and can thus occur at higher viscosities. According to the Williams-Landel-Ferry equation (Williams et al., 1955), viscosity of the amorphous lactose phase can be described as a function of the temperature difference between the actual temperature and the glass transition temperature. This suggests that it is this temperature difference, and not the actual temperature or humidity, that determines stickiness. This hypothesis was validated by Paterson et al. (2005) for stickiness of amorphous lactose powder, who observed indeed the temperature difference above the glass transition temperature was the dominant factor determining stickiness.

When considering multicomponent dairy ingredient powders such as milk powder, whey powder, or whey permeate powder, strong correlations between glass transition temperature and stickiness are observed (i.e., in all cases, glass transition temperature needs to be exceeded to induce stickiness; Schuck et al., 2005; Fitzpatrick et al., 2007; Hogan and O'Callaghan, 2010, 2013; Silalai and Roos, 2010). However, whereas glass transition temperatures are, as outlined previously, determined primarily by moisture content and not as much by lactose content, stickiness of powders shows a considerably stronger dependence on lactose content as well. In general, powders with higher lactose content are more prone to become sticky (Hogan and O'Callaghan, 2010; Silalai and Roos, 2010), as are powders containing hydrolyzed rather than intact protein (Hogan and O'Callaghan, 2013), despite often showing comparable glass transition temperature at a particular relative humidity. This necessitates placing powder stickiness not only in the perspective of glass transition temperatures, but also in the perspective of powder particle surface composition. Stickiness of powder particles is a surface phenomenon and surface composition is thus more important than bulk composition. As outlined previously, lactose is typically underrepresented at the powder particle surface and the proportion of powder surface covered by lactose increases with increasing proportion of lactose in the powder. Hence, powders containing high levels of lactose are more susceptible to developing stickiness when the temperature exceeds the glass transition temperature sufficiently far to develop viscous flow of the lactose on the particle surface such that bridges can form. The higher stickiness of powders containing more lactose (Hogan and O'Callaghan, 2010) or protein hydrolysates (Hogan and O'Callaghan, 2013) rather than intact proteins can also be understood when considering that the proportion of lactose on the particle surface is higher in the powders containing hydrolysates.

The time dependence of stickiness development is important to keep in mind when interpreting analytical results. Methods for stickiness measurement were reviewed by Adhikari et al. (2001) and O'Callaghan and Hogan (2013) and highlight a wide variety of methods conducting measurements over time scales ranging from seconds to minutes or hours. Stickiness development over hours cannot be directly translated to events occurring at the time scale of spray drying, but are useful for considering stickiness development during storage. For estimating stickiness development during spray drying techniques such as the particle gun (Paterson et al., 2007; Zuo et al., 2007; Murti et al., 2009), methods involving time scales of seconds are more representative. One important consideration, however, to take into account when determining stickiness is that in virtually all cases powder humidity is increased with 
the aim of finding a combination of temperature and humidity where stickiness is observed due to the glass transition from solid to liquid. However, when placing stickiness in the context of a drying process, it should be kept in mind that the opposite actually occurs (i.e., the product is desorbed and the glass transition in this case is from liquid to solid rather than from solid to liquid). Hence, sorption isotherm hysteresis as described by Kinsella et al. (1986) should also be considered here. Schuck et al. (2005) suggested that the susceptibility of powders to stickiness or caking could be predicted based on the temperature increment above the glass transition temperature and the change in heat capacity associated with the glass transition.

\section{Lactose-Induced Caking}

As outlined above, caking may be considered an advanced state occurring after powders have become sticky and involves the formation of solid bridges between particles (Aguilera et al., 1995; Listiohadi et al., 2005; Kelly, 2009). Solidification of the bridges can occur as a result of cooling below the glass transition temperature. In addition, solid bridges can form as a result of crystallization of lactose in the liquid bridges under conditions outlined previously (i.e., increased temperature and humidity). Once initiated, crystallization rate can increase exponentially, due to the fact that amorphous lactose binds more water than the crystalline forms of lactose, and thus causes an increase in humidity, should this occur in the closed environment. Preventing caking of milk powder, whey powder, and permeate powder during storage is essential to retain desired handling properties. Sufficiently low moisture content combined with controlled storage conditions have commonly been suggested to prevent or minimize caking during storage (Aguilera et al., 1995; Listiohadi et al., 2005; Kelly, 2009). However, although this typically suffices for milk powders, it is insufficient to prevent caking in whey powders.

Pre- and postcrystallization of lactose (i.e., before and after the drying step, respectively) have been applied to ensure that noncaking whey powders can be obtained (Roetman, 1979). Precrystallization occurs after concentration of the product to an extent where lactose becomes supersaturated and crystallization can take place, either spontaneously or by the addition of seeding crystals. Typically, the product is concentrated on an evaporator, followed by flash-cooling to $\sim 30^{\circ} \mathrm{C}$; subsequently, the evaporate is cooled further to $\sim 10^{\circ} \mathrm{C}$ at a rate of $\sim 2$ to $3^{\circ} \mathrm{C}$ per hour. The cooling profile is essential to ensure that sufficient lactose crystallizes and that the crystals have the required size (i.e., small and uniform). Selection of the cooling profile involves a trade-off between the maximum yield of crystallization, which is higher at lower temperature, and crystallization speed, which is higher at higher temperatures. An optimized cooling profile will facilitate up to 75 to $80 \%$ of lactose being crystallized in cheese whey. As the crystallization process is effectively driven by mass transport to the surface of the growing crystal (Wong and Hartel, 2014), viscosity is an important aspect to control. Avoiding a high heat-load to the whey before crystallization is important to control viscosity. In addition, lactate can be a strong contributor to thickening of acid whey concentrates (Mimouni et al., 2007). Calcium lactate crystals were found to form in concentrated acid whey, which increased viscosity drastically, regardless of the presence of proteins or lactose crystals.

As the lactose crystallization process is a lengthy process, options have been investigated to accelerate the process, particularly the nucleation stage. McLeod et al. (2010) used flow through venturi orifices to initiate nucleation in supersaturated lactose solutions and observed a strong relationship between nucleation rate and the number of vortices created in the system. They suggested that the vortices induced by flow through the venturi orifices reduced the required distance for molecular diffusion in the system. This mechanism may also explain the enhanced nucleation of lactose observed by Dincer et al. (2014) in aqueous solution and Zisu et al. (2014) in concentrated whey.

\section{CONCLUSIONS}

Phase transitions of lactose can be the cause of significant powder handling issues in dairy ingredients (e.g., stickiness during processing or caking during storage). However, understanding these phase transitions and the effect of matrix properties thereon can be applied to avoid or at least minimize these issues. The glass transition of amorphous lactose is a crucial parameter in this respect; it is determined by temperature and relative humidity, which are key control parameters. The presence of other constituents (e.g., milk proteins) in dairy ingredients affects both the rate of moisture uptake as well as the composition of the surface layer of the particles, where the caking and sticking occur. Control of processing conditions, storage conditions, and powder particle properties are therefore crucial to control lactose behavior in ingredients and associated powder handling properties.

\section{REFERENCES}

Adhikari, B., T. Howes, B. Bhandari, and V. Truong. 2001. Stickiness in foods: A review of mechanisms and test methods. Int. J. Food Prop. 4:1-33. 
Aguilera, J., J. del Valle, and M. Karel. 1995. Caking phenomena in amorphous food powders. Trends Food Sci. Technol. 6:149-155.

Berlin, E., B. Anderson, and M. Pallansch. 1968. Water vapor sorption properties of various dried milks and wheys. J. Dairy Sci. 51:1339-1344.

Bhargava, A., and P. Jelen. 1996. Lactose solubility and crystal growth as affected by mineral impurities. J. Food Sci. 61:180-184.

Bronlund, J., and T. Paterson. 2004. Moisture sorption isotherms for crystalline, amorphous and predominantly crystalline lactose powders. Int. Dairy J. 14:247-254.

Brooks, G. F. 2000. The sticking and crystallisation of amorphous lactose. M.E., Massey University, Palmerston North, New Zealand.

Butler, B. 1998. Modeling industrial lactose crystallisation. PhD Thesis. University of Queensland, Brisbane, Australia.

Dincer, T., B. Zisu, C. Vallet, V. Jayasena, M. Palmer, and M. Weeks. 2014. Sonocrystallisation of lactose in an aqueous system. Int. Dairy J. 35:43-48.

Downton, G. E., J. L. Flores-Luna, and C. J. King. 1982. Mechanism of stickiness in hygroscopic, amorphous powders. Ind. Eng. Chem. Fund. 21:447-451.

Drapier-Beche, N., J. Fanni, and M. Parmentier. 1999. Physical and chemical properties of molecular compounds of lactose. J. Dairy Sci. 82:2558-2563.

Fäldt, P., and B. Bergenståhl. 1994. The surface composition of spraydried protein-Lactose powders. Colloid. Surface. A 90:183-190.

Fäldt, P., and B. Bergenståhl. 1996. Changes in surface composition of spray-dried food powders due to lactose crystallization. Food Sci. Technol. LEB 29:438-446.

Fäldt, P., and I. Sjöholm. 1996. Characterization of spray-dried whole milk. Milchwissenschaft 51:88-90.

Fitzpatrick, J., M. Hodnett, M. Twomey, P. Cerqueira, J. O'Flynn, and Y. Roos. 2007. Glass transition and the flowability and caking of powders containing amorphous lactose. Powder Technol. 178:119-128

Foster, K. D., J. E. Bronlund, and A. H. Paterson. 2005. The prediction of moisture sorption isotherms for dairy powders. Int. Dairy J. 15:411-418

Fyfe, K., O. Kravchuk, A. V. Nguyen, H. Deeth, and B. Bhandari. 2011. Influence of dryer type on surface characteristics of milk powders. Dry. Technol. 29:758-769.

Gänzle, M. G., G. Haase, and P. Jelen. 2008. Lactose: Crystallization, hydrolysis and value-added derivatives. Int. Dairy J. 18:685-694

Gernigon, G., F. Baillon, F. Espitalier, C. Le Floch-Fouéré, P. Schuck, and R. Jeantet. 2013. Effects of the addition of various minerals, proteins and salts of organic acids on the principal steps of $\alpha$-lactose monohydrate crystallisation. Int. Dairy J. 30:88-95.

Gordon, M., and J. S. Taylor. 1952. Ideal copolymers and the secondorder transitions of synthetic rubbers. I. Noncrystalline copolymers. Rubber Chem. Technol. 26:323-335.

Guu, Y., and R. Zall. 1992. Nanofiltration concentration effect on the efficacy of lactose crystallization. J. Food Sci. 57:735-739.

Haase, G., and T. Nickerson. 1966. Kinetic reactions of alpha and beta lactose. I. Mutarotation. J. Dairy Sci. 49:127-132.

Haque, M., and Y. Roos. 2004a. Water sorption and plasticization behavior of spray-dried lactose/protein mixtures. J. Food Sci. 69:E384-E391.

Haque, M. K., and Y. Roos. 2004b. Water plasticization and crystallization of lactose in spray-dried lactose/protein mixtures. J. Food Sci. 69:FEP23-FEP29.

Haque, M. K., and Y. H. Roos. 2006. Differences in the physical state and thermal behavior of spray-dried and freeze-dried lactose and lactose/protein mixtures. Innov. Food Sci. Emerg. Technol. 7:6273.

Hodges, G. E., E. K. Lowe, and A. H. J. Paterson. 1993. A mathematical model for lactose dissolution. Chem. Eng. J. 53:B25-B33.

Hogan, S., and D. O'Callaghan. 2013. Moisture sorption and stickiness behaviour of hydrolysed whey protein/lactose powders. Dairy Sci. Technol. 93:505-521.

Hogan, S. A., and D. J. O'Callaghan. 2010. Influence of milk proteins on the development of lactose-induced stickiness in dairy powders. Int. Dairy J. 20:212-221.
Holsinger, V. 1997. Physical and chemical properties of lactose. Pages 1-38 in Advanced Dairy Chemistry. Vol. 3. P. F. Fox, ed. Springer, New York, NY.

Ibach, A., and M. Kind. 2007. Crystallization kinetics of amorphous lactose, whey-permeate and whey powders. Carbohydr. Res. 342:1357-1365.

Ihli, J., and A. Paterson. 2015. Effect of galacto-oligosaccharide concentration on the kinetics of lactose crystallisation. Int. Dairy J. 41:26-31.

Islam, M. I.-U., M. Edrisi, and T. Langrish. 2013. Improving process yield by adding WPI to lactose during crystallization and spray drying under high-humidity conditions. Dry. Technol. 31:393-404.

Jelen, P., and S. T. Coulter. 1973a. Effects of certain salts and other whey substances on the growth of lactose crystals. J. Food Sci 38:1186-1189.

Jelen, P., and S. T. Coulter. 1973b. Effects of supersaturation and temperature on the growth of lactose crystals. J. Food Sci $38: 1182-1185$.

Jouppila, K., J. Kansikas, and Y. Roos. 1998. Factors affecting crystallization and crystallization kinetics in amorphous corn starch. Carbohydr. Polym. 36:143-149.

Jouppila, K., and Y. Roos. 1994a. Glass transitions and crystallization in milk powders. J. Dairy Sci. 77:2907-2915.

Jouppila, K., and Y. Roos. 1994b. Water sorption and time-dependent phenomena of milk powders. J. Dairy Sci. 77:1798-1808.

Kelly, P. M. 2009. Significance of Lactose in Milk Powders. Pages 80-97 in Advanced Dairy Chemistry. Vol. 3. P. McSweeney and P. F. Fox, ed. Springer, New York, NY.

Kim, E. H.-J., X. D. Chen, and D. Pearce. 2002. Surface characterization of four industrial spray-dried dairy powders in relation to chemical composition, structure and wetting property. Colloid Surface. B 26:197-212

Kim, E. H.-J., X. Dong Chen, and D. Pearce. 2003. On the mechanisms of surface formation and the surface compositions of industrial milk powders. Dry. Technol. 21:265-278.

Kinsella, J. E., P. F. Fox, and L. B. Rockland. 1986. Water sorption by proteins: Milk and whey proteins. Crit. Rev. Food Sci. Nutr. 24:91-139.

Lai, H. M., and S. J. Schmidt. 1990. Lactose crystallization in skim milk powder observed by hydrodynamic equilibria, scanning electron microscopy and $2 \mathrm{H}$ nuclear magnetic resonance. J. Food Sci. 55:994-999.

Lifran, E., T. Vu, R. Durham, J. Hourigan, and R. Sleigh. 2007. Crystallisation kinetics of lactose in the presence of lactose phosphate. Powder Technol. 179:43-54.

Listiohadi, Y., J. Hourigan, R. Sleigh, and R. Steele. 2005. An exploration of the caking of lactose in whey and skim milk powders. Aust. J. Dairy Technol. 60:207-213.

Lowe, E. K., and A. H. J. Paterson. 1998. A mathematical model for lactose dissolution, Part II. Dissolution below the alpha lactose solubility limit. J. Food Eng. 38:15-25.

Marcus, Y. 2010. Effect of ions on the structure of water. Pure Appl Chem. 82:1889-1899.

McLeod, J., A. Paterson, J. Bronlund, and J. Jones. 2010. Nucleation of alpha lactose monohydrate induced using flow through a venturi orifice. J. Cryst. Growth 312:800-807.

McLeod, J., A. Paterson, J. Jones, and J. Bronlund. 2011. Primary nucleation of alpha-lactose monohydrate: The effect of supersaturation and temperature. Int. Dairy J. 21:455-461.

Mikkonen, H., P. Helakorpi, L. Myllykoski, and R. L. Keiski. 2001. Effect of nanofiltration on lactose crystallisation. Milchwissenschaft 56:307-309.

Mimouni, A., S. Bouhallab, M. Famelart, D. Naegele, and P. Schuck. 2007. The formation of calcium lactate crystals is responsible for concentrated acid whey thickening. J. Dairy Sci. 90:57-65.

Mimouni, A., P. Schuck, and S. Bouhallab. 2005. Kinetics of lactose crystallization and crystal size as monitored by refractometry and laser light scattering: Effect of proteins. Lait 85:253-260.

Mimouni, A., P. Schuck, and S. Bouhallab. 2009. Isothermal batch crystallization of alpha-lactose: A kinetic model combining mutarotation, nucleation and growth steps. Int. Dairy J. 19:129-136. 
Mounsey, J., S. Hogan, B. Murray, and D. O'Callaghan. 2012. Effects of hydrolysis on solid-state relaxation and stickiness behavior of sodium caseinate-lactose powders. J. Dairy Sci. 95:2270-2281.

Murti, R. A., A. T. H. Paterson, D. L. Pearce, and J. E. Bronlund. 2009. Stickiness of skim milk powder using the particle gun technique. Int. Dairy J. 19:137-141.

Nijdam, J., A. Ibach, K. Eichhorn, and M. Kind. 2007. An X-ray diffraction analysis of crystallised whey and whey-permeate powders. Carbohydr. Res. 342:2354-2364.

O'Callaghan, D., and S. Hogan. 2013. The physical nature of stickiness in the spray drying of dairy products - A review. Dairy Sci. Technol. 93:331-346.

Omar, A. E., and Y. H. Roos. 2007a. Water sorption and time-dependent crystallization behaviour of freeze-dried lactose-salt mixtures. Food Sci. Technol. LEB 40:520-528.

Omar, A. E., and Y. H. Roos. 2007b. Glass transition and crystallization behaviour of freeze-dried lactose-salt mixtures. Food Sci. Technol. LEB 40:536-543.

Paterson, A. 2009. Production and uses of lactose. Pages 105-120 in Advanced Dairy Chemistry. Vol. Volume 3. P. L. H. McSweeney and P. F. Fox, ed. Springer, New York, NY.

Paterson, A., G. Brooks, J. Bronlund, and K. Foster. 2005. Development of stickiness in amorphous lactose at constant $\mathrm{T}-\mathrm{T} \mathrm{g}$ levels. Int. Dairy J. 15:513-519.

Paterson, A., G. Ripberger, and R. Bridges. 2015. Measurement of the viscosity of freeze dried amorphous lactose near the glass transition temperature. Int. Dairy J. 43:27-32.

Paterson, A. H., J. E. Bronlund, J. Y. Zuo, and R. Chatterjee. 2007. Analysis of particle-gun-derived dairy powder stickiness curves. Int. Dairy J. 17:860-865.

Peleg, M. 1992. On the use of the WLF model in polymers and foods. Crit. Rev. Food Sci. Nutr. 32:59-66.

Roetman, K. 1979. Crystalline lactose and the structure of spray-dried milk products as observed by scanning electron miscroscopy. Neth. Milk Dairy J. 33:1-11.

Roos, Y., and M. Karel. 1992. Crystallization of amorphous lactose. J. Food Sci. 57:775-777.

Roos, Y. H. 2002. Importance of glass transition and water activity to spray drying and stability of dairy powders. Lait 82:475-484.

Roos, Y. H. 2010. Glass transition temperature and its relevance in food processing. Annu. Rev. Food Sci. Technol. 1:469-496.
Saito, Z. 1988. Lactose crystallization in commercial whey powders and in spray-dried lactose. Food Microstruct. 7:75-81.

Schuck, P., E. Blanchard, A. Dolivet, S. Méjean, E. Onillon, and R. Jeantet. 2005. Water activity and glass transition in dairy ingredients. Lait 85:295-304.

Shrestha, A. K., T. Howes, B. P. Adhikari, B. J. Wood, and B. R. Bhandari. 2007. Effect of protein concentration on the surface composition, water sorption and glass transition temperature of spray-dried skim milk powders. Food Chem. 104:1436-1444.

Silalai, N., and Y. H. Roos. 2010. Roles of water and solids composition in the control of glass transition and stickiness of milk powders. J. Food Sci. 75:E285-E296.

Smart, J. 1988. Effect of whey components on the rate of crystallization and solubility of $\alpha$-lactose monohydrate. New Zeal. J. Dairy Sci. 23:275-289.

Smart, J. B., and J. M. Smith. 1992. Effect of selected compounds on the rate of $\alpha$-lactose monohydrate crystallization, crystal yield and quality. Int. Dairy J. 2:41-53.

Visser, R. 1984. Experiments for tracing growth retarders in lactose. Neth. Milk Dairy J. 38:107-133.

Visser, R. 1988. Crystal growth retarding of alpha-lactose hydrate by sugar phosphates; a continued study. Neth. Milk Dairy J. 42:449 468

Walstra, P., and R. Jenness. 1984. Dairy Chemistry and Physics. John Wiley and Sons, Hoboken, NJ.

Walstra, P., J. T. Wouters, and T. J. Geurts. 2005. Dairy Science and Technology. Second ed. CRC Press, Boca Raton, FL.

Williams, M. L., R. F. Landel, and J. D. Ferry. 1955. The temperature dependence of relaxation mechanisms in amorphous polymers and other glass-forming liquids. J. Am. Chem. Soc. 77:3701-3707.

Wong, S. Y., and R. W. Hartel. 2014. Crystallization in lactose refining-A review. J. Food Sci. 79:R257-R272.

Zisu, B., M. Sciberras, V. Jayasena, M. Weeks, M. Palmer, and T. D. Dincer. 2014. Sonocrystallisation of lactose in concentrated whey Ultrason. Sonochem. 21:2117-2121.

Zuo, J. Y., A. H. Paterson, J. E. Bronlund, and R. Chatterjee. 2007. Using a particle-gun to measure initiation of stickiness of dairy powders. Int. Dairy J. 17:268-273. 